\title{
Knowledge as Explanandum: Disentangling Lay and Professional Perspectives on Science and Religion
}

Tom Kaden, York University

Stephen Jones, Centre for Science, Knowledge and Belief in Society, Newman University

Rebecca Catto, Department of Sociology, Kent State University

Fern Elsdon-Baker, Centre for Science, Knowledge and Belief in Society, Newman University

NOTE: This is a pre-production version of an article accepted for publication in the journal Studies in Religion/Sciences Religieuses.

\begin{abstract}
Issues pertaining to the relationship between science and religion, like creationism, Intelligent Design, and New Atheism, are increasingly the focus of social scientific research. This research often does not differentiate clearly between different kinds of social actors. At the most basic level, professional developers and distributors of systems of thought that deal with the relationship between science and religion and laypeople who take up this knowledge, or parts of it, must be distinguished. Based upon interview material from the large, multinational study Science and Religion: Exploring the Spectrum, we identify five typical dimensions of lay knowledge vis-á-vis professional knowledge: reinterpretation of professional labels; neglect of important parts of knowledge systems; addition of knowledge; lower ascription of relevance; and an individual ethical framing.
\end{abstract}

Keywords: Science and religion, Creationism, Intelligent Design, Conflict thesis, Sociology of Knowledge

Abstract (French translation) 
Les interrogations liées à la relation entre science et religion, tells que le créationnisme, le dessein intelligent ou le nouvel athéisme, font de plus en plus l'objet de recherches en science sociale. Ces recherches bien souvent ne différencient pas clairement les différents sortes d"acteurs sociaux. Au niveau le plus élémentaire, il faut distinguer les développeurs professionnels des distributeurs de systèmes de pensée qui traitent de la relation entre science et religion, ainsi que des personnes athées qui adoptent ce savoir, ou du moins certains de ses aspects. D’après les interviews menées par la vaste étude multinationale "Science and Religion: Exploring the Spectrum" nous identifions cinq dimensions typiques du savoir laïque vis-à-vis des connaissances professionnelles: la réinterprétation des étiquettes professionnelles; la négligence de parties majeures des systèmes de connaissance; l'ajout de connaissances; une plus faible attribution de la pertinence; et un cadre éthique individuel.

Keywords: Science et religion, Richard Dawkins, créationnisme, Intelligent Design, these conflit, sociologie de la connaisance 
A veritable industry has grown up around "science vs. religion" debates since the late nineteenth century. The ability of this subject matter to excite public and professional passions does not appear to be on the wane. However, only relatively recently has "science and religion" as a social phenomenon become a subject of study. Social scientific research about the relationship between science and religion is, in part, concerned with problems that specifically relate to the basic distinction between laypeople and professionals. There are several ways to delineate both groups. In this article we employ a substantial definition of professional actors in the thematic field of science and religion, identifying them as people whose vocation it is to publicly develop, distribute, defend, and critique systems of explanation that relate science to different systems of ultimate belief. This means that professional expertise in either science or religion does not necessarily constitute professional status in the field of "science and religion". For example, scientists can often remain laypeople when it comes to the highly-specialized discourse surrounding science and religion. An evolutionary biologist who may need to discuss religious responses to evolution on an everyday basis in the classroom is, to all intents and purposes, a layperson in this domain, in much the same way they may cover the history of Charles Darwin in lectures without claiming to be a historian. A relational definition of this professional discourse adds to this the feature that professionals are those who are seen by, and are in communication with, other professionals. For instance, in the USA there is a network of specialized actors from the creationist and anti-creationist milieus who, to a large extent, perform and shape the public debate about science and religion, perpetuating it through permanent communication with and about each other (see Kaden 2016, forthcoming; Aechtner 2014, 2016). These professionals can equally be non-scientist and scientist: the defining factor is that they claim the status of public representatives and they are put forward in public forums as representatives of a philosophical position. Alternatively, they might act as a public focus for these communities or those holding a position at odds with their own. In contrast, laypeople can be defined as non-scientists or scientists who do not share these features. They do not publically represent a philosophy or community and are not considered to represent a particular philosophical position or community of belief. Although, as we find in other knowledge domains, the boundary between layperson and professional can in places be 
blurred, within science and religion debates there is a distinct difference in the nature, complexity and tenor of the discourse within the lay and professional spheres.

The empirical relation between expert and lay knowledge about science and religion is unclear in its makeup and consequences for both laypeople and professionals. For instance, professionals, laypeople, the media, and social scientists make use of labels that denote positions on the relationship between science and religion, but the status of these labels is ambiguous for all of these groups. On the one hand, terms like "Young Earth Creationism", "Theistic Evolution", "Intelligent Design", or "New Atheism" refer to relatively internally coherent explanatory systems that are developed by professionals and that often contain highly complex arguments about such diverse things as geology, the human mind, biological species, and the interpretation of religious texts (Numbers 2006, Kaden 2016, Scott 2005, Forrest \& Gross 2003). On the other hand, these labels appear in public discourse and are indeed in some cases used by nonprofessionals to describe their own views or those of others. These labels are also used in social scientific research, especially polls, as terms that describe the views of particular people or groups (cf. Elsdon-Baker 2015). In applying them, both media and researchers often assume that there is correspondence between the professional and lay understanding of these terms.

This assumption has been challenged by recent social scientific criticism of how professional and lay knowledge about the relationship between science and religion is conceptualized. In this article, we will discuss this criticism, and provide empirical material and analysis that shows that it is adequate both in its rejection of prior concepts and its suggestions of more suitable alternatives. We will further refine and support this new strand of thinking by showing that there also exists a variety of empirical constellations in which professional knowledge can enter laypeople's views. While often being vague and contradictory when compared to the "official" professional versions of science-and-religion positions, lay knowledge in certain aspects can achieve a depth that equals that of professionals. Such lay people remain lay, despite their select items of deep knowledge, as they are not viewed as being in positions of expertise or authority in relation to science and religion within their wider communities of interest. This can be termed „lay professionalization“. These bits of deep knowledge can coexist with relative ignorance of other aspects of a particular knowledge system. From the viewpoint of those who have built their expertise around 
developing or rejecting that system, these neglected aspects appear as equally important. Moreover, the depth and coherence of knowledge are not necessarily connected with a positive attitude towards the knowledge system in question and, in fact, not even with a particular interest in the relationship between science and religion.

This paper will also address the question why that is the case. What biographical factors shape the way knowledge of science and religion is acquired, neglected, or altered? Few qualitative social scientific studies have touched upon this issue, investigating different "ways of knowing" that play a role when people deal with the relationship between science and religion (Doolin and Motion 2010). It will become clear that specific biographical constellations can create interests that motivate dealing with certain aspects of certain knowledge systems while not necessarily considering other aspects of the same systems. We present cases that show how ethical concerns from various fields of life can function as a motivator and/or catalyst for dealing with science-and-religion issues.

\section{Current social scientific revisions of existing frameworks}

We will follow and go beyond recent social scientific research that has put a critical focus on existing frameworks, to capture the dynamics of debates about science and religion. Jonathan Hill (2014a) has shown, with regard to the situation in the United States, that lay and professional understandings rarely correspond, and that in consequence the use of these terms is misleading when it comes to doing empirical qualitative and quantitative research about science and religion. Hill's starting point is an ideal, coherent creationist knowledge system that consists of the following claims: biological evolution is false; God created humans; humans are descended from a literal Adam and Eve; God created them ex nihilo; and the earth was created in six 24-hour-days. Hill tested all these elements as items on the American population in his National Study of Religion \& Human Origins. When asked about their adherence to creationist positions in surveys like Gallup's Values and Beliefs Survey, usually about $40 \%$ answer in the affirmative. ${ }^{1}$ Hill shows, however, via his disaggregation of the knowledge system of Young Earth Creationism, that the number of people who actually hold creationist views shrinks the more elements are added. In fact, while around $40 \%$ agree to the claim that "God created human beings pretty much in their present form at one time within

\footnotetext{
${ }^{1}$ See http://www.gallup.com/poll/170822/believe-creationist-view-human-origins.aspx
} 
the last 10,000 years or so" only eight percent agree to all elements of the actual knowledge system that Gallup's question is supposed to represent. So in terms of how they see the role of knowledge, Gallup is close to the view of the organized professional developers of "Young Earth Creationism" that epistemic claims are at the heart of the creation/evolution controversy. However, this also means that the way in which Gallup and other polling companies frame the issue is at odds with the perceptions of the general public (whose opinion they are supposed to be measuring) as Hill's research suggests they are much less focused on the issues of incompatible truth claims. Celebrity creationist Ken Ham's organization Answers in Genesis ${ }^{2}$ argues that to believe in a recent creation of humans by God is in fact but one element of a coherent view of God and the Bible that also entails the other elements that were explicated in Hill's study.

John H. Evans, a leading social scientific scholar of science and religion, describes this problem with regard to the epistemological conflict narrative (Evans \& Evans 2008, Evans 2011). This narrative claims that science and religion have been in conflict over competing truth claims for as long as humans have engaged in scientific inquiry, and that this determines the relationship between scientific and religious actors. The conflict narrative has been subject to growing scholarly criticism since the 1970s (see Evans \& Evans 2008, Lightman 2001, Numbers 2009, Brooke \& Cantor 2000), but despite this public polling agencies like Gallup, and many social scientists, struggle to reflect this criticism in their research designs (ElsdonBaker 2015). The question Evans asks in a forthcoming publication is thus: Why is the epistemological conflict narrative relatively firmly established in public debates despite its empirical untenability? Some of the answers Evans suggests directly pertain to the relationship between expert and lay knowledge.

Evans states that "elites may have conflict, and the masses may not, due to different forms of reasoning in the two groups" (Evans, forthcoming). The knowledge of science-and-religion experts, such as professional creationists, is highly systematic: the knowledge creationists have about the Genesis flood, the origin of species, the dating of rocks and fossils, etc. is intertwined and forms a relatively coherent whole that is supported by a small number of overarching principles of reasoning, such as the infallibility of the Bible and the necessity to interpret it literally. Likewise, professionals on the other side of the worldview spectrum

\footnotetext{
${ }^{2}$ See https://answersingenesis.org/about/faith/
} 
integrate a wealth of actual and inferred knowledge about the world via principles like materialism or naturalism. It is characteristic of professional science-and-religion actors from this part of the spectrum to extend the reach of these principles beyond their immediate area of expertise, and to argue for an atheistic interpretation of the universe. According to Evans, it is this focus on systematic explanations of the world that dominates professional discourse. The reason for this is not intrinsic to the subject-matter of the debates, however. Instead, intellectualism of this sort characterizes all elite discourses, including in the social sciences. This elective affinity between two intellectualist elites who are concerned with the same topic leads, in Evans' view, to a systematically distorted picture of the coherence of lay belief and the nature of conflict between science and religion. We agree with Evans' analysis of the differences in epistemic styles between laypeople and elites, but, as indicated earlier, we draw the line differently between the two groups. Instead of proposing that different styles of reasoning permeate all intellectual elites in the same way (which would lead to scientists, as members of an 'elite', to always look for systematic explanations), we argue that these styles are limited to professional discourses and specific areas of life, their use depending on factors that might not have anything to do with intellectual consistency.

In any case, whatever the scope of these distortions, they point to the fact that lay discourses are structured in a fundamentally different way. They are not subject to the same standards of rationality and coherence, which is why contradictions between various truth claims are more likely. ${ }^{3}$ According to Evans, this combines with the fact that experts, be they professional science-and-religion actors or social scientists concerned with analyzing the debates surrounding science and religion, tend to focus more on statements that concern explanations of the world, whereas laypeople are more concerned with what Evans calls the "social/moral" aspects of the issues at hand. This means that logical contradictions - for example, selective religious opposition to science - can persist in lay contexts without being regarded as points of conflict (Evans 2011). Due to the epistemic focus of experts, however, such selective moral opposition tends to be generalized into an overarching knowledge conflict, which in turn leads to a gross overstatement of conflict between science and religion.

\footnotetext{
${ }^{3}$ The concept of „rationality“ employed in this analysis is a "relational“ one (see Weber 2001: xxxviii ff.). This means that what is rational depends on the set of presuppositions that varies from actor to actor. It is hence not possible to characterize creationists (or atheists, for that matter) as irrational solely because their knowledge of the world is at odds with other, dominant systems of world explanation, like modern secular science.
} 
Someone professionally involved in creation/evolution issues sees a logical contradiction between the information that they have about the human genetic code and the creationist Christian belief that a few thousand years ago a pair of humans stood at the beginning of all humanity. A Christian layperson, in our definition, might believe in the existence of Adam and Eve but still visit a doctor to have a genetic test performed, and he will not feel this contradiction because he does not make use of an overarching principle that coordinates the various fact claims that populate his world. It is this lack of coordination that is at the bottom of Hill's observations: truth claims that cannot be separated from each other from a professional vantage point may very well be selectively believed by laypeople. In Evans' perspective, these observations might be traced back to a confusion of modes of knowledge.

\section{Current research on knowledge in science-and-religion debates}

Evans' and Hill's work is part of a more recent turn toward a critical approach to the primacy of epistemic difference in debates about science and religion that is turning a longstanding discussion in new directions. As the discussion of the Gallup poll above shows, many studies have been influenced by public representations of science and religion without indicating it or even realizing it (cf. McCain \& Kampourakis 2016; Elsdon-Baker 2015). It is, therefore, necessary to revisit some of the recent studies of science-and-religion to explore the extent to which Evans' diagnosis about the epistemic bias of social science holds true, before moving on to presentation and analysis of our own data.

When social science asks what counts as conflict between science and religion, the answers have often in the past applied "symbolic analyses" to science and religion, viewing them "as systems of ideas, beliefs, or discourses" (Evans and Evans 2008: 91). More recent quantitative and qualitative social scientific research shows, however, that knowledge is often indeed merely a dependent factor in science-and-religion debates, and not an explanatory category. With regard to the general social acceptance of science, this aspect has been discussed in various social scientific disciplines for a long time. In Science and Technology Studies (STS), the incongruence between acceptance and understanding of scientific facts is a longstanding topic (Wynne 1992; Sturgis and Allum 2004). Generally, STS considers knowledge only one dimension that influences science-related conflicts in society, with trust (in scientific authority) and general attitudes towards science being two others (cf. Bauer et al. 2007). Studies that concerned the creation/evolution controversy from an STS perspective found 
little evidence that a knowledge deficit plays a decisive role in shaping rejection of evolution, though it is not entirely irrelevant (Hildering et al. 2013).

A section of social scientific research about science and religion deals with the role science knowledge plays in connection with various value orientations. For instance, when religious people take issue with certain scientific developments, their position is often not predominantly dependent upon how much they know about the science. Rather, while knowledge and understanding are, of course, not meaningless, their beliefs hinge on nonepistemic aspects like their level of religious conservativism and commitment, or the values, structure and sanctioning options of the community. In some cases, these non-epistemic factors lead to the opposite of what would be expected within the epistemological conflict paradigm. For instance, believers in a literal interpretation of the Bible tend to reject preimplantation genetic testing even more when they know more about it (Allum et al. 2014). Similarly, increased factual knowledge of the theory of evolution does not lead to an increase of acceptance of it among American Biblical literalists but, on the contrary, increases the likelihood of them calling for the teaching of creationism in science classes (Baker 2013). This is in line with findings relating to broader public perceptions about controversial aspects of science and technological development, which suggest that having more knowledgeable citizens does not necessarily lead to a more positive attitude towards those scientific or technological developments (Bauer 2008).

Qualitative research has its own ways of dealing with the issue of why knowledge is not always efficacious in explaining anti-evolutionary sentiments. Long (2011), in an ethnographic analysis of American creationist students, has shown how rejection of evolution is linked with questions of existential, social, and emotional stability. Hildering et al. (2013) suggest that there are different levels of knowledge, and that, in the case of rejection of evolution, religious knowledge stands against scientific knowledge and trumps it - although for all respondents in their study, science continues to be valued highly in all other respects. As a matter of fact, the respondents in this study, Dutch creationists, make an effort to wrest evolution from the realm of science, which, among other things, serves to keep their general esteem of science intact. This moves the discussion somewhat closer toward a critical assessment of the status of knowledge itself in the sense that Evans suggests and that Hill exercises. Distinguishing between various levels of knowledge can be fruitful to assess their 
structure and relative hierarchy, but it does not help explain why levels of knowledge are structured the way they are. Hence, it merely shifts the problem. Still, Hildering and colleagues point in the right direction when they state that "[a]rguments drawn from science are merely viewed as an addition to a decision that is already made and serve as a rationale to a non-rational decision" (Hildering et al. 2013: 997).

Some research suggests that such structuring might be influenced to a large extent by the stability of the social environment. Quantitative research by Hill (2014a, 2014b) found that the view that the Bible is inerrant only predicts adherence to creationism when it goes together with belonging to a congregation that rejects evolution. In general, Hill argues, that stable, committed creationist social networks are more important than the learning of facts and education as a predictor of creationist convictions.

Research along the same lines has also extended beyond the boundaries of Christianity to Islam and yields similar results. Pierre Clément (2013) discovered considerable variation in a quantitative analysis of Muslim teachers' stance on evolution and creation in several Western and Islamic countries. He holds that the factor that might best explain this variation is whether or not evolution is part of a broader narrative of Western domination. Other research by Clément et al. (2013: 18) shows that creationism "is often linked to more essentialism, sexism, homophobia and also xenophobia, and evolution with the opposite values". This constitutes further evidence that the basis for antievolutionism is not to be sought in the factual basis or criticism of the theory of evolution alone.

With regard to the main questions of this paper - What role does professional science-andreligion knowledge play in nonprofessionals' reasoning and views, and what factors influence this role? - several things become apparent. Most of the examples show that knowledge of science or religion only rarely determines the position of laypeople. It is not what people know about science and religion, including their own religion, that determines their stance toward important issues concerning the relationship of both. Rather, knowledge, or reference to knowledge systems, is influenced by a number of value orientations and associated factors, like cultural identity, social stability and social ethics. This conclusion underlines the necessity to distinguish between two levels of discourse, which has already been mentioned by Evans. Similar to Evans' differentiation, Taber and colleagues (2011a, b) have distinguished between a philosophical or professional and a "ground level" in their research. Here, at the lay level, 
informal, contradictory, and ad hoc notions of science and religion can be encountered (Taber et al. 2011b: 1019). ${ }^{4}$

Beyond this basic distinction it seems necessary to differentiate further within the "ground level". It cannot be expected that all laypeople display the same lack of interest in questions of truth or textual interpretation. Indeed, we shall show that there is variation and selective interest that relates to a range of social, biographical and ethical factors. Social scientific research about science and religion can at this point get beyond its current self-critical stage and gain new insights into the complex relationship between professional and lay knowledge, as well as the content of both, on the basis of current conceptual revisions.

Methods

Our contribution to these fundamental debates expands the view beyond the United States, where the main research foci of Hill, Evans, and most other contemporary scholars who study science and religion lies. The cases that are discussed in this paper are drawn from a large qualitative data set of 123 semi-structured interviews with members of the public and life scientists ${ }^{5}$ from the UK and Canada. These were gathered in the course of the ongoing, largescale, cross-disciplinary project Science and Religion: Exploring the Spectrum (2014-2017).

The goal of the project was to investigate how debates about and perceptions of science and religion are socially embedded. The data set is split approximately 1:1 between the UK and Canada $^{6}$ and 2:1 between members of the general public and scientists working in the life sciences. The sample consists of approximately the same number of religious as non-religious participants ${ }^{7}$ and the same number of men as women. We selected participants purposively to ensure maximum variation in terms of religious tradition, age, class and ethnicity, with the specific targets for inclusion varying depending on the category (Emmel 2014). In the case of

\footnotetext{
${ }^{4}$ This differentiation between expert and lay discourse is also supported by Uecker and Lucke (2011) who show that contentious culture wars issues are only treated as such among elites like clergy rather than among the general population.

${ }^{5}$ This included research scientists working within the life sciences, biology and medical fields.

${ }^{6}$ UK interviews and focus groups were conducted predominantly in the North West and West Midlands of England. The majority of the Canadian interviews were conducted in Ontario.

${ }^{7}$ Needless to say, this division is very crude and masks the substantial differences in our sample in terms of levels of practice, strength of belief and manner of identification. There was a substantial "middle ground" that eluded simple classification into one of these two sides.
} 
interviews and focus groups with members of the public, this was facilitated by the use of a pre-screening survey that was advertised through leafleting, distribution via social media and emails to a range of voluntary organizations with and without an interest in this subject area. This allowed participants to be invited on the basis of the characteristics above and their interest in science and/or religion. We used the answers to the pre-screening survey to avoid over-representation of individuals who maintain a personal interest in public debates on science and religion. We ensured that our interviewees have at least completed education up to age 18 to ensure basic knowledge of evolutionary theory. While this purposive approach and the inclusion criteria limit the scope of our findings somewhat, we might anticipate that those with lower levels of education are less familiar with, and influenced by, professional debates about science and religion.

Interviews covered participants' religious or non-religious formation, interest in the sciences, views on the subject of science and religion and perceptions of public coverage of science and religion. Interviews were semi-structured, following a set script that was common to the interviews in the UK and Canada but that allowed participants leeway to elaborate their views. This loose structure was designed to give participants the scope to draw associations between themes (Wengraf 2001). While interviewees' were, in keeping with this method, allowed to use their discretion about question order and phrasing, we did ensure that participants were asked questions on personal influences and public debate, such as: "What, or who, has influenced your understanding of, and perspective on, evolutionary science?"; "What are your thoughts on the present debate about religion and evolutionary science?"; and "Are there any particular public figures you see as being particularly trustworthy or authoritative on issues to do with evolutionary science and belief?"

The interviews and focus groups were recorded, transcribed, and analyzed using the data analysis program NVivo. Coding was performed by the interviewers (authors Kaden and Jones). An initial coding scheme was set out based upon the broad research questions of Science and Religion: Exploring the Spectrum. In order to analyse themes emerging in the interview that were unanticipated, however, the interviewers reviewed a limited selection of interviews before revisiting the coding structure and adding nodes accordingly. All nodes were agreed collectively by the research team, with continuous dialogue between project team members being sustained to facilitate inter-coder reliability (Campell et al 2013). The 
characteristics described below did not serve as coding categories themselves, but rather emerged from analysis of categories relating to language and labels, public figures, and the role of evidence in belief, as well as a review of interview summaries. While we contend that the broad trends that we identify below can be found throughout the dataset and beyond it, the cases we present are not meant to be typical in the sense of being representative of people's views. Rather, they are typical in the sense that they display the trends we see in a clear, if individually shaped, way. With this in mind, it must be noted that with the exception of one person (Joanne), all individuals are educated, white Christians or atheists, which engenders structural distortions pertaining to these traits. The patterns we identify in the empirical section of this article are certainly found among those without degree education, and minorities, but these cases were distinctive in ways that we do not have space to do justice to here.

Empirical forms of knowledge systems vis-à-vis "ideal" or "complete" professional knowledge systems

The revision of social scientific research about the relationship between science and religion hinges, besides the critical treatment of prior conceptualizations, on the adequate integration of empirical material. Attempts to draw conclusions about public perceptions on the basis of the knowledge and order of relevance set by professionals are fraught with fundamental problems and, hence, rather obscure the view. This is why here we propose proceeding in the opposite direction. The question we ask is: in which way, and in what order of relevance, does systematic knowledge about how science and religion relate exist in non-professional actors' narratives of their reasoning and stances in relation to science and religion ${ }^{8}$ And, What form does this knowledge take in comparison with professionally developed systems like Intelligent Design or New Atheism?

This question becomes particularly relevant because in our data sample, references to professionals, that is, public figures who engage professionally in discussions about the relationship between science and religion, were widespread. The majority of our respondents

\footnotetext{
${ }^{8}$ There is insufficient space here to touch upon the related question of where the laypeople gained their knowledge, i.e., the transfer of knowledge between both levels of discourse. It will be addressed in future publications.
} 
referred to one or more public figures, ${ }^{9}$ in some cases displaying in-depth knowledge of their views on science and religion. Stances toward these figures varied widely, as well as the scope and motivation for dealing with their views. Taken together, these references suggest that, at least among more educated populations, there is a strong link between the lay and professional levels, and the discussion below serves as an attempt to characterize the links between these two levels in a systematic manner.

A typology of "shapes" that knowledge systems can take in comparison to their ideal, complete form, as developed by professionals, can be determined via this method. While this comparison says little about actual transfer of knowledge between professionals and laypeople, $^{10}$ it makes visible the complexity that studies which presuppose a relatively straightforward relationship lack.

This is why the focus will now be placed on laypeople in our sample who treated systematic knowledge about science and religion in different ways, based on their different interests, beliefs, and knowledge. ${ }^{11}$ Among the views we discuss are two scientists, who, as discussed above, while being a professional in their field of evolutionary biology and medicine, are laypersons when it comes to professionally developed knowledge systems that deal with the relationship between science and religion.

Five significant characteristics of lay concepts of science-and-religion that distinguish them from professional ideal types will be described. They do not classify individual stances in their entirety, but, rather, constitute general traits that can be found in various combinations across our data. Individuals might display one or more of these characteristics, but the entire sample is permeated by them. They can be summarized as follows:

\footnotetext{
${ }^{9}$ These included, among others: Alister McGrath, Bertrand Russell, Carl Sagan, Bill Nye, Francis Collins, Richard Dawkins, Lawrence Krauss, Stephen C. Meyer, PZ Meyers, Christopher Hitchens, Douglas Futuyma, Francisco Ayala, Thomas Szasz, Neil deGrass Tyson, Sam Harris, Daniel Dennett, James Randi, Michael Behe, Ken Miller, Eugenie Scott, Michael Ruse, Ken Ham, Denis Lamoureux, Simon Conway Morris, Todd Wood, and Tony Wright. ${ }^{10}$ There is only incipient research about this kind of top-down causation; notably, Aechtner $(2014,2016)$ has analyzed the persuasiveness of creationist and anti-creationist media.

${ }^{11}$ While this is not the focus of this article, we want to emphasize that lay professionalization is one out of a number of different ways in which interviewees related to professional science-and-religion knowledge, and to basic knowledge about evolution and religion in general. Based upon their intellectual skills, interests, and biographical situation, as discussed below, lay professionalization is but one response found amongst respondents. Within our total sample, less informed views, lack of basic knowledge of evolution and science, as well as general lack of interested in the topic were present as well.
} 
1. Knowledge systems are often reinterpreted by laypeople, even, and maybe especially, by those who possess a comprehensive understanding of them, in order to be compatible with personal views. These reinterpretations can also contain criticism of the reinterpreted knowledge system itself.

2. Elements of knowledge systems that are crucial in the opinion of the professionals who developed them can be missing or neglected in laypeople's articulated reasoning and stances in relation to science and religion, although they can be conscious of the gaps that result from this neglect.

3. Some people are fairly consistent in their views on science and religion, but specific bits of knowledge from other positions are added to their views that cannot be explained with reference to professional or scholarly definitions of the position they state they hold.

4. Professional creators and upholders of science-and-religion knowledge systems do not only care about the content of their systems; they are also convinced that the understanding and acceptance of the system is very important, and the knowledge they convey very relevant. For instance, there is no creationist knowledge system that is not on a fundamental level connected with social-moral and worldview questions in such a way that the social order is at least supported, if not guaranteed, through the assent to the creationist thought system. On the other hand, its rejection is said to lead to all kinds of social evils. The same emphasis on the broader relevance of knowledge systems can be found among the developers of sciencebased atheistic systems. Compared with this universal assertion of relevance of systematic knowledge, the relevance laypeople ascribe to these systems varies more broadly. There are laypeople, for instance highly committed secular humanists or creationists, who place scientific knowledge or religious doctrine as a keystone to their own identity and worldview. In many other cases, laypeople ascribe a significantly lower relevance to the knowledge systems, often even in cases where they share the general social/moral outlook of their producers.

5. Our fifth characteristic is located on a different plain than the other four. With Evans, we find that ethical factors influence the first four points, motivating selections of knowledge. So instead of being concerned with how people relate to professional science-and-religion knowledge, this characteristic describes why they do it. The split between professionals and 
laypeople is mirrored in this area as well. Ethical considerations of laypeople to take up or reject certain parts of professional knowledge systems are not, in the cases discussed below, identical with the ethical justifications that the professionals offer. Rather, individual ethical needs from their own lives motivate the way they treat knowledge systems. In particular, professional knowledge is sometimes drawn on as part of the processes of developing a moral identity or sense of self as good. Alternatively, encounters with difference and conflict prompt the search for knowledge for strategic and practical purposes.

We will now provide and discuss examples for each of these five characteristics of lay knowledge.

\section{Reinterpretation of labels}

When viewed as systems of knowledge, positions on evolution and religion are usually presented as coherent concepts like "Intelligent Design" or "Young Earth Creationism", but as Hill has shown (Hill 2014a, b; see above), and as our research confirms, people only very rarely subscribe to labels that represent such distinct systems of thought on science-andreligion. In our interviews, even in cases where participants said that they adhered to a specific position, frequently they explicitly modified these concepts, an example being Walker, a Canadian medical professor.

While Walker is not a professional when it comes to relating science and religion, his own personal and professional interests put him in the vicinity of this category. His belief has changed in the course of his life from Young Earth Creationism to Theistic Evolutionism, and he still finds himself debating friends and members of his congregation about these issues. These disputes have led him to write a book about theological and scientific aspects of the creation/evolution controversy. In the introduction of the book, he cites two reasons for dealing in a detailed manner with issues surrounding science and religion. The first is the ever-growing weight of scientific evidence that goes against the conservative doctrines he grew up with. While Walker managed to keep his beliefs separate from his work as a medical researcher and reader of scientific literature for a long time, this cognitive separation eventually became too much for him to ignore. The second reason is ethical. Walker became increasingly aware that many of the stories in the Old Testament are at odds with common 
moral standards, and with the image of God as benevolent and loving. He draws parallels between God's commanding to slaughter the Canaanites and contemporary news reports of slaughter in the Middle East, writing that the moral outrage about the latter should also apply to the former. While he deals with issues of science and religion in-depth in his book, Walker remains a lay person in relation to professional science and religion knowledge systems, because he is not seen as an authority or expert in public discourse on the subject, and dealing with science and religion is not his actual vocation.

When we asked Walker to comment on Intelligent Design he answered:

I'm very wary of - so, on one level I'll say yes, I believe in intelligent design, on one level. And by that I mean if I believe that God created everything, and I believe God is intelligent, then whatever he did was intelligently designed, right? But I'm very wary of not allowing the ID idea to become this "God of the gaps" answer, just because something is really, really complicated and hard to design, hard to understand.

He then goes on to explain that the examples for intelligent design that are put forward by Intelligent Design proponents fall under the "God of the gaps" category, meaning that God, when viewed primarily as a force that is active in nature, is reduced to occupying the gaps left by science (cf. Drummond 1904). In Walker's view this weakens the plausibility of God's existence if the gaps are then filled by scientific discoveries. In this instance, both "ID" and "God of the gaps" are formulations that stem from professional discourses, and Walker's answer betrays the confidence of someone who knows about the ins and outs Intelligent Design as an established knowledge system in the creation/evolution debates (see Behe 2006, Meyer 2009, Forrest and Gross 2003).

The positions on science and religion and the way they are represented in people's lives do not, indeed, seem to be systems of knowledge that people apply to their various experiences. On the contrary, in our research knowledge systems appeared to be developed only to the extent that various life-world requirements make this necessary. This is shown by the following examples that involve individual additions or deletions of parts of systematic knowledge to otherwise consistent positions. 
People who are very knowledgeable about science-and-religion, and hold firm positions, may not only reinterpret labels and criticize some professional views, as John did. They might also neglect aspects of the very position they themselves hold, and that are regarded as crucial by the professional creators and maintainers of those positions.

This is the case for George. He can be regarded as a very knowledgeable representative of a Christian perspective on evolution and religion. A Canadian Anglican lay reader ${ }^{12}$ in his 50 s, he is very active in his congregation. He also has had a lifelong interest in animals and, specifically, in what role they play in God's creation, having previously published an extensive volume that reviews the Bible's position on animals quote by quote. However, similarly to Walker, this book was not published by an established publisher and has not become part of professional theological or science and religion discourse. George is not viewed as being in a position of expertise or authority in relation to science and religion within his wider community of interest.

George nevertheless subscribes to a very clear-cut theological position called Progressive Revelation, which holds that God gradually reveals Himself and His plans to humankind as it progresses. This will lead to an eventual confluence of all religions on earth, as well as the realization that science and religion point toward the same truth. This is why George emphasizes commonalities between the scientific and religious endeavors. At the most basic level, this entails the interpretation of evolution as God's way of creating:

I personally believe beyond a shadow of a doubt that God created the world and evolution is how he did it, or does it. Is still doing it. It's an ongoing process. Not... [snaps fingers] bingo, I have an oak tree. We had to start with an acorn. Bingo, I have a chicken. Unfortunately we have to start with an egg. At some point, some ancient bird related to dinosaurs became the first African peahen or whatever. It became the progenitor of all chickens, who far outnumber us by the way. There's more than six billion or seven billion chickens in the world. And we treat them like they're nothing.

\footnotetext{
${ }^{12}$ In Anglicanism, a lay reader is a layperson who is authorized by the Bishop to lead certain parts of service, like reciting the Litany, and, in some cases, conducting funerals.
} 
This quote reveals a close link between science and ethics; arguments drawn from science undergird George's ethical stance. He links his argument with ethical teachings in other world religions, thus creating a coherent picture:

If people are still going to keep chickens and penitentiaries for birds, until somebody says, I won't buy them anymore unless they live at least a reasonable life before they're killed, watch how quickly those cages disappear. The cruelty disappears. [...] And cruelty, according to the scriptures, according to the most advanced religions is in fact anathema. [...] But we still do when it comes to other species because, well, they're other species.

George's thinking displays a close and informed connection between science, ethics, and religions. From this, one would expect his views on the relationship between evolution and religion to be consistent and congruent with the position that he subscribes to - and to a large extent they are. Yet on what can be considered the central contentious point when relating evolution and Christianity, he answers completely contrary to this expectation:

Q: One scientist who, actually, as a result of his own research started to doubt his own religious beliefs was Charles Darwin who [...] asked himself how a benevolent God in which he believed could create via such a messy and cruel process. So wouldn't evolution then contradict the principle of non-cruelty?

A: Yes, that's true.

Q: And what would be your ...?

A: There are questions that I can't answer. Even as an amateur theologian, at least in one field, I do not pretend to be a theologian in another field.

Like Walker, George's view comes close to a systematic, knowledge-based position on science and religion. But here an element is missing that usually is considered crucial in professional circles when it comes to deciding whether there is conflict between evolution and Christianity, or science and religion more generally. While it is not unusual for empirical philosophical outlooks to be inconsistent, it is nonetheless surprising that in this case an interest, position, and a belief system is maintained by George while he recognizes that his philosophy is not comprehensive. 


\section{Addition}

Joanne represents the opposite in terms of her general interest in science-and-religion issues, but in this she displays a similar individual autonomy with regard to professional knowledge systems. She is fairly consistent in her views on science and religion, but specific bits of knowledge from other positions are added to her views that cannot be explained with reference to her stated position.

Joanne is a biology professor at a Canadian research university. Born in Jamaica, and raised Catholic, she says she never really felt engaged with her faith. When she read Bertrand Russell's "Why I am not a Christian" (Russell 1967), which a lab partner gave her during her graduate studies, she took the step to call herself an atheist, a position she says she had already held for a long time without committing to it. She describes herself as having always had a very science-like way of thinking and approaching the world, and makes clear that this way of thinking is incompatible with religiosity:

The existence of God is the same as the existence of leprechauns or unicorns. We have no evidence that the world works that way. It's not to say that I wouldn't take in evidence if it exists or if - but at the moment - I don't say I'm agnostic about leprechauns. So I wouldn't say I'm agnostic about God. Because for me I have the same amount of evidence for both of those, and I live a very evidence-based life I guess in some ways.

The odd element in her otherwise fairly consistently disengaged position towards the relationship between science and religion is Joanne's strong interest in creationism. Her interest in this developed in reaction to religious students engaging her in her introductory classes on evolutionary theory. She recalls an instance of this she found particularly striking.

But the other viewpoint which I got actually from a fundamentalist Muslim a few years ago was - he started to cry in my office, he said "I came into this class thinking I was gonna knock down every piece of evidence you gave us, and I got nothing, and I don't know what to do, because this is contrary to everything I've been taught, and this makes sense." It was kind of heartrending. 
She goes on to describe other instances of students taking issue with evolution. In reaction to this she has developed a routine in terms of creationism that has led to an acquisition of quasi-professional knowledge of it:

And so, literally, I would google the night before "creationists" and whatever my topic was, and I'd find a list of questions, and I [would think], "Yeah, I know the answers to all of those", and then I'm going to class and I'm totally prepared for those. And I would get a lot of them.

Joanne is an otherwise religiously uninterested person who has developed expertise on creationism and learnt about theological alternatives due to her commitment to teaching evolution. She is expert on a knowledge system that she does not subscribe to, and the knowledge she acquired did nothing to alter her views. She is even more knowledgeable of the knowledge system she does not subscribe to than of the system she adheres to. She does not follow or participate in public debates on evolution and religion, and she says she has not read the publications of the New Atheists, whose views she claims to support to the extent that she knows about them. Many of her friends are Christians, and while she disagrees with their views, they adopted a "live and let live" attitude. This makes her taking up this knowledge more of a strategic response to the creationists' claims that enter her life-world. Her decision to deal with it, motivated as it is by her work ethics, is hence value-rational (cf. Weber 1978).

\section{Relevance and Uncertainty}

It becomes apparent when looking at the cases discussed thus far that professional knowledge is attributed only selective, and in some cases minor, relevance. George sees great relevance in certain aspects of the relationship between science and religion, but neglects others that are of relevance in the public discourse of professionals (see for example Peters and Hewlett 2003). Many of the publicly debated arguments that support Joanne's views about how science and religion relate are not personally relevant to her. Instead she deals in great detail with aspects of a knowledge system that she does not accept. Her knowledge of these issues is acquired strategically for educational and (to an extent) polemical purposes. 
The individual ascription of relevance is, we can see, a factor that can determine the role, and even the existence of, professional knowledge in the reasoning and positions of laypeople. Relevance may, however, not be ascribed at all. In Hill's already mentioned study, many people who accepted creationist truth claims also felt that it is not very important whether their views of creation are actually correct. A similar disinterest could be found in our own research. Nick, for example, is a young British medical doctor whose Christian belief intensified during his years of study. When asked whether he is at all interested in conflicts between science and religion, he develops the following thought:

So I think, I'd say my faith was mostly based on sort of the evidence that I could see, for Jesus principally, because that's more recent than evidence for things maybe written back in the Genesis. And, because I think that evidence is quite strong, then that makes me believe in Jesus and what he said, so I believe in God the Father as well. Then, when I look at the sort of evidence that...so Jesus saying that all the scriptures are true, then that means that Genesis is true. Things like the creation story and I was... particularly Genesis, but it's the greatest story where you've got animals put on Earth, and you've got a universe made in seven days it's quite in conflict with the Big Bang theory and evolution. But I'd say mainly I don't care, because I think that, because I trust Jesus so much, then, likely these stories are symbolic, and I can't say that for certain, and obviously the very strong evidence is that evolution is how all the animals came here, and it may be that in the future someone manages to pick that theory apart, but it certainly seems unlikely.

In this case it can be seen how knowledge about the relationship between science and religion, its relevance and its ability to influence decisions, is negligible in comparison with other knowledge, i.e., of Jesus's role as savior. Relevance is thus an indispensable factor in the assessment of empirical constellations. This leads directly to the next questions, namely, what generates relevance? What reasons do people have to deal with the relationship between science and religion to the extent that they do, or to specifically neglect it? 
The question of what factors determine the relationship of laypeople to professional knowledge systems about science and religion has already been treated by Evans. As stated at the beginning of this paper, he sees social and moral factors as dominant over epistemic ones. Instead of coming to be a creationist through being persuaded by geological, biological and hermeneutical arguments, many people hold creationist views due to reasons that have more to do with personal and group identity, a feeling of cultural threat, and a supposed link between evolution and amorality (cf. Long 2011, Toumey 1994, Eve \& Harrold 1991).

This relevance structure also applies to the acquisition of professional knowledge by nonprofessional actors. The examples discussed above show that laypeople regard professional knowledge systems not just as something that they can accept or reject in their entirety. Instead, they take up specific bits of knowledge, and sometimes achieve an expertise in certain areas that renders them quasi-professionals. At the same time it is clear that the propositional content of their views on how science and religion relate is not something that interests them for its own sake. Rather, they are interested in it as a response to very individual problems and biographical constellations.

Moral or ethical problems can be regarded as a common basis in the examples discussed above. For George, the confrontation with ethical problems is deeply linked with his engagement with the Bible, animals, and evolution:

Q: So this interest in animals, was it connected to religious ideas from the very start?

A: Well, I can remember being approximately five or six years old, and I put this in the introduction that I wrote for the book. I said to my parents, who's God? [...] Then I went to Sunday School and there was this picture of this man with a lamb on his shoulder. This was the Good Shepherd. The man who was, according to John, the lamb of God who takes away the sin of the world. Why, I ask, did Jesus become a lamb? [...] Jesus said, I am the good shepherd. Jesus becomes the Pascha lamb. And dies for the sins of mankind, but not just for the sins of mankind, for the whole of creation. You find that in the New Testament, and it's completely overlooked. He didn't just die for us. He died for them and for the whole of creation. [...] $[T]$ here is no place that says, but that doesn't apply when it comes to animals. It's 
universal. [...] So when you're dealing with the ox as well as your own son, do you not immediately pull him out of the pit if happens to fall into it on a Sabbath? Well of course you do. Because you're supposed to be compassionate. You're supposed to be loving. You're supposed to be kind.

Hence, for George it was ethical problems that determined his selection of knowledge, and led him to wrestle in-depth with Biblical hermeneutics and science. His interest in professional knowledge finds its limit where his ethical questions cease to be relevant. For George, in order to justify a Biblically sound ethical relationship to the non-human creation it is not necessary to determine further the relationship between creation and evolution. This is why his urge to know does not extend to this area of professional knowledge, even though the professionals themselves see it as central.

Ethical concerns are at play in Joanne's case, too, that bring her to deal with a knowledge system against her personal disinclination and own beliefs. In her interest to impart the content of her teaching to her students in an efficient and plausible way, she deals with the intricacies of creationist knowledge systems, and refutes them to the extent that enables her to perform academic teaching that fits her work ethics. In addition, she informs herself about possibilities to negotiate belief and science, however this, too, is not a result of her own interest but is supposed to provide her with tools to make the acceptance of the scientific knowledge she provides easier for her students.

While Walker emphasizes the growing burden of keeping his conservative religious views and his science knowledge in two different compartments of his mind as the key factor that lead him to think more deeply about science and religion, he also mentions the moral conundrum of reconciling the gruesome stories in many books of the Old Testament with his faith, and the general ethical standards of his time.

As might be expected, our interview with Nick revealed little that would speak for an ethical or moral motivation to deal specifically with the relationship between science and religion. He makes clear, however, that his attending church in general has an ethical dimension, because it puts him in contact with fellow Christians. "I hope that I can be an encouragement to people when I'm there." But since he has little interest in how science and religion relate, and 
accepts that the Genesis account is symbolic, the ethical motivation which he does have does not feed his interest into this issue.

\section{Conclusion}

The role professionally developed knowledge about the relationship between science and religion plays for the interviewed Canadian and British laypeople is complex and multifaceted. In concurrence with recent criticism it has become clear that knowledge as an explanatory category is only of low relevance. Discussion of prior research has shown that knowledge about science and religion, like specific creationist arguments about the geological consequences of the Flood, or the New Atheists' naturalistic explanations of religion, do very little to convince laypeople of views that they do not already hold or are sympathetic towards for other reasons. But analysis of empirical material from Science and Religion: Exploring the Spectrum shows that lay knowledge can, at times, be as differentiated and epistemically focused as that of professionals. This diagnosis makes it all the more important to look for the basis of this selection and relevance ascription by laypeople.

One result of this analysis is that it has confirmed the view of Evans and other scholars that ethical or social/moral concerns play a key role for the selection and relevance ascription of knowledge. In this way, knowledge ceases to be an explanatory category and becomes a factor that is to be explained. This work builds upon and advances Evans' distinction between laypeople and professionals, as well as Taber and colleagues' general description of lay knowledge, as less coherent than professional views. We propose that ethical motives not only mark an important difference between the positions of laypeople and professionals, but in some cases can lead to a selective affinity between the structure and relevance ascription of laypeople's knowledge and that of professionals. In the cases discussed above, ethical concerns about animals, Biblical stories, current world events and teaching biology students lead to laypeople gathering quasi-professional knowledge in certain parts of knowledge systems about science and religion.

Participants discussed in this article all have degrees. Indeed, Joanne is an academic scientist and Nick a medical doctor. Hence they may be considered members of a social elite. Yet, they remain lay when it comes to professional science and religion knowledge systems. Our 
broader sample indicates that laypeople with no interest and low educational attainment can still also have some awareness of such systems, albeit limited perhaps to awareness of public figures such as Richard Dawkins.

Further research is necessary to gain a better understanding of these kinds of "lay professionalization". What ideal and practical considerations guide laypeople in their selection of professional knowledge sources? In particular, how do ethical concerns, which we identified as an important motivator for lay professionalization, guide selection and relevance-setting of professional knowledge? What makes laypeople see professionals as authoritative?

Labels like "Intelligent Design", "New Atheism", "Theistic Evolution", and the public debates that are often connected with them might in some cases provide laypeople with a number of terms, categories, arguments and value orientations, but not necessarily with the coherence and social/moral links that are intended by its creators. Understanding these terms as discursive resources that people use rather than terms in which people can be categorized provides one way of reintroducing the agency and creativity of publics into science and religion debates.

\section{References}

Aechtner T (2014) Darwin-skeptic mass media: examining persuasion in the evolution wars. Journal of Media and Religion, 13 4: 187-207.

Aechtner, T (2016) Challenging the Darwin Skeptics: Examining Proevolutionist Media Persuasion. Journal of Media and Religion, 15(2): 78-99.

Allum N, Sibley E, Sturgis P and Stoneman P (2014) Religious Beliefs, Knowledge about Science and Attitudes towards Medical Genetics". Public Understanding of Science 23(7): 83349.

Baker JO (2013) Acceptance of Evolution and Support for Teaching Creationism in Public Schools: The Conditional Impact of Educational Attainment. Journal for the Scientific Study of Religion 52(1): 216-28. 
Bauer, MW, Allum, N and Miller, S (2007) What have we learnt from 25 years of PUS research

- liberating and widening the agenda. Public Understanding of Science, 16 (1), pp. 79-95.

Bauer, MW (2008) Survey research and the public understanding of science. In Bucchi M and Trench B (eds) Handbook of public communication of science and technology. London: Routledge, pp. 111-13

Behe M (2006) Darwin's Black Box. The Biochemical Challenge to Evolution. New York: The Free Press.

Brooke J and Cantor G (2000) Reconstructing Nature. The Engagement of Science and Religion. Oxford: Oxford University Press.

Campbell J L, Quincy, C, Osserman, J and Pedersen, O (2013) Coding In-depth Semistructured Interviews: Problems of Unitization and Intercoder Reliability and Agreement. Sociological Methods and Research 42(3): 294-320.

Clément P (2013) Muslim Teachers' Conceptions of Evolution in Several Countries. Public Understanding of Science 24(4): 400-421.

Clément P, Quessada MP and Castéra J (2013) Creationism and Innatism of Teachers in 26 Countries. Journal INEDP 1(1): 2013.

Dawkins R (2006) The God Delusion. London: Bantam Press.

Doolin B and Motion J (2010) Christian Lay Understandings of Preimplantation Genetic Diagnosis. Public Understanding of Science 19(6): 669-85.

Drummond H (1904) The Ascent of Man. New York: James Pott \& Co.

Elsdon-Baker F (2015) Creating Creationists: The Influence of „issues Framing“ on Our Understanding of Public Perceptions of Clash Narratives between Evolutionary Science and Belief. Public Understanding of Science 24(4): 422-39.

Emmel N. (2014) Sampling and Choosing Cases in Qualitative Research. London: Sage.

Eve RA and Harrold FB (1991) The Creationist Movement in Modern America. Boston: Twayne Publishers. 
Evans JH and Evans MS (2008) Religion and Science: Beyond the Epistemological Conflict Narrative. Annual Review of Sociology 34(1): 87-105.

Evans JH. (2011) Epistemological and Moral Conflict between Religion and Science. Journal for the Scientific Study of Religion 50(4): 707-27.

Evans JH (forthcoming) The Public's Views of the Relationship between Religion and Science and Proposed Reasons Why the Idea Will Not Die. In: Numbers RL and Hardin J (ed) The Idea that Wouldn't Die: The Warfare Between Science and Religion. Baltimore: Johns Hopkins University Press.

Forrest B and Gross PR (2003) Creationism's Trojan Horse: The Wedge of Intelligent Design. New York, Oxford University Press.

Hildering P, Consoli L and van den Born R (2013) Denying Darwin: Views on Science in the Rejection of Evolution by Dutch Protestants. Public Understanding of Science 22(8): 988-98.

Hill J (2014a) National Study of Religion and Human Origins. Grand Rapids: BioLogos Foundation.

Hill J (2014b) The Recipe For Creationism. Available at: http://biologos.org/blog/the-recipefor-creationism (Accessed 11 April 2017)

Kaden T (2016) „Thousands... Not Billions!“: Professional Creationists and Their Opponents in the United States. Zeitschrift für Theologie und Gemeinde 21: 277-289.

Kaden T (forthcoming) Creationism in the United States. A Sociology of the Conflict Between Professional Creationists and Anti-Creationists, 1960 - 2013. New York: Springer.

Lightman B (2001) Victorian Sciences and Religions: Discordant Harmonies. Osiris, Science in Theistic Contexts: Cognitive Dimensions 16: 343-66.

Long DE (2011) Evolution and Religion in American Education: An Ethnography. Dordrecht: Springer.

McCain K and Kampourakis K (2016) Which question do polls about evolution and belief really ask, and why does it matter? Public Understanding of Science. DOI: 
10.1177/0963662516642726.

Meyer SC (2009) Signature in the Cell: DNA and the Evidence for Intelligent Design. London: HarperOne.

Numbers RL (2006) The Creationists. Cambridge: Harvard University Press.

Numbers RL (2009) Galileo Goes to Jail and Other Myths about Science and Religion. Cambridge: Harvard University Press.

Peters, T and Hewlett, MJ (2003) Evolution from Creation to New Creation: Conflict, Conversation, and Convergence. Nashville: Abingdon Press.

Russell B (1967) Why I Am Not a Christian and Other Essays on Religion and Related Subjects. London: Touchstone.

Scott E (2005) Evolution vs. Creationism: An Introduction. Berkeley: University of California Press.

Sinatra GM, Southerland SA, McConaughy F and Demastes JW (2003) Intentions and Beliefs in Students" Understanding and Acceptance of Biological Evolution. Journal of Research in Science Teaching 40(5): 510-28.

Sturgis, P and Allum N (2004) Science in Society: Re-Evaluating the Deficit Model of Public Attitudes. Public Understanding of Science 13(1), pp. 55-74.

Taber K, Billingsley B, Riga F and Newdick H (2011a) To What Extent Do Pupils Perceive Science to Be Inconsistent with Religious Faith? An Exploratory Survey of 13-14 Year-Old English Pupils. Science Education International 22(2): 99-118.

Taber K, Billingsley B, Riga F and Newdick H (2011b) Secondary Students" Responses to Perceptions of the Relationship between Science and Religion: Stances Identified from an Interview Study. Science Education 95(6): 1000-1025.

Toumey CP (1994) God's Own Scientists: Creationists in a Secular World. New Brunswick: Rutgers University Press.

Uecker JE and Lucke G (2011) Protestant Clergy and the Culture Wars: An Empirical Test of 
Hunter's Thesis. Journal for the Scientific Study of Religion 50(4): 692-706.

Weber, M (1978) Economy and Society: An Outline of Interpretive Sociology. Berkeley: UC Press.

Weber M (2001) Author's Introduction. In: The Protestant Ethic and the Spirit of Capitalism. London: Routledge.

Wengraf T (2001) Qualitative Research Interviewing: Biographic Narrative and SemiStructured Methods. London: Sage.

Wynne, B (1992) Public Understanding of Science Research: New Horizons or Hall of Mirrors? Public Understanding of Science 1(1), pp. 37-43. 